\section{Commentary: Management of cardiac paraganglioma is a team sport}

\author{
Kevin L. Greason, MD
}

No one is big enough to be independent of others. - Dr William Worrall Mayo ${ }^{1}$

Readers involved in the treatment of patients with complex cardiac tumors will be interested in this nicely written article on the rare condition of cardiac paraganglioma by Chan and colleagues. ${ }^{2}$ Although the focus is on patient and operative characteristics, the article also provides a general overview of the disease and the institutional multidisciplinary heart team's philosophy on evaluation and management.

The study provides a review of a single institution and surgeon experience (MJR) in 19 patients undergoing surgery from 2004 to 2020 . No patient received embolization. The operation was often complex, requiring aortic root replacement in 4 patients $(21 \%)$ and autotransplant in $8(42 \%)$. All patients had complete gross tumor resection. Operative mortality occurred in 2 patients $(11 \% ; 1$ intraoperative). No patient experienced local recurrence of disease, but 1 died of metastatic disease. Survival was $72 \%$ at 3 years.

Additional data and analysis provide several important observations. Two patients had previous emergency sternotomy for control of needle biopsy related bleeding and cardiac tamponade. Metabolically active tumors were present in 6 patients $(32 \%)$. Complications were frequent and included blood transfusion (16 patients, median of $5 \mathrm{U}$ ), renal failure, cardiac tamponade, need for mechanical circulatory support, prolonged ventilation, tracheostomy, and vocal cord paralysis. Median length of stay in the intensive care unit was 204 hours (my calculation from the authors' Table 2) and hospital was 14 days.

From the Department of Cardiovascular Surgery, Mayo Clinic, Rochester, Minn. Disclosures: The author reported no conflicts of interest.

The Journal policy requires editors and reviewers to disclose conflicts of interest and to decline handling or reviewing manuscripts for which they may have a conflict of interest. The editors and reviewers of this article have no conflicts of interest.

Received for publication Oct 4, 2020; revisions received Oct 4, 2020; accepted for publication Oct 6, 2020; available ahead of print Oct 27, 2020.

Address for reprints: Kevin L. Greason, MD, Department of Cardiovascular Surgery,

Mayo Clinic, 200 First St, Rochester, MN (E-mail: greason.kevin@mayo.edu).

J Thorac Cardiovasc Surg 2022;164:167-8

$0022-5223 / \$ 36.00$

Copyright (c) 2020 by The American Association for Thoracic Surgery

https://doi.org/10.1016/j.jtcvs.2020.10.015

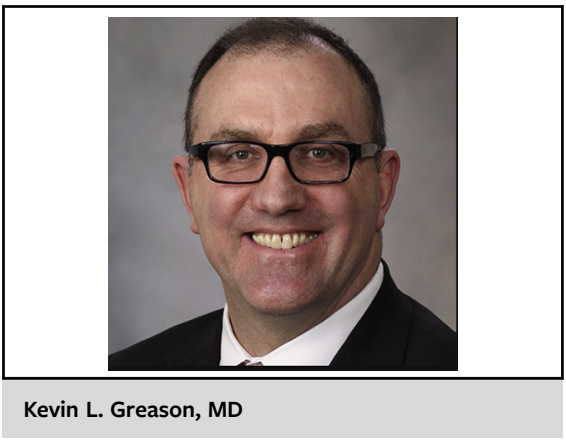

CENTRAL MESSAGE

Cardiac paraganglioma is a rare and complex disease that often requires complex operative techniques and mechanical circulatory support. A multidisciplinary heart team approach is required.

The main strength of this article is the focused analysis of a rare disease. It is kind of a military postdeployment briefing on lessons learned in the management of 19 patients over 16 years by a single surgeon. The discussion section gives an overview of the pathology, imaging, perioperative management, genetics/malignancy, and multidisciplinary heart team approach. The surgical takeaway is that operations should be tailored to tumor location, size, and structures involved to achieve complete resection. ${ }^{2}$

The limitations of the study are appropriately outlined by the authors. The small number of patients, retrospective methodology, and referral bias are reflective of the rarity of the disease. Similar confines have been present in other recently published focused institutional experiences. ${ }^{3,4} \mathrm{~A}$ perceived weakness of these studies is an apparent lack of address on what to do about bleeding. ${ }^{2-4}$ Safe and successful embolization has been reported. ${ }^{5}$ Why not do preoperative embolization? My review of the authors' associated video leads me to believe the patient would have been an ideal candidate for preoperative embolization.

Chan and colleagues ${ }^{2}$ have added to our understanding of this rare disease. I believe a consensus is present that mandates a multidisciplinary heart team approach to these patients' condition. A magnetic resonance imaging scan should be done before biopsy of any heart tumor. All patients should be genetically screened and medically managed. Preoperative embolization should be considered. Effective surgical resection, complex reconstruction, and need for mechanical circulatory 
support should be thoroughly planned for to optimize success. Complete surgical resection is the treatment.

\section{References}

1. Sharing Mayo Clinic: Mayo Brothers' wisdom. Available at:. Accessed October 4, 2020. . Available at: https://sharing.mayoclinic.org/mayo-brothers-wisdom/

2. Chan EY, Ali A, Umana JP, Nguyen DT, Hamilton DJ, Graviss EA, et al. Management of primary cardiac paraganglioma. J Thorac Cardiovasc Surg. 2022;164:158-66.e1.
3. Gurrieri C, Butz JJ, Weingarten TN, Bancos I, Young WF, Cassivi SD, et al. Resection of intrathoracic paraganglioma with and without cardiopulmonary bypass. Ann Thorac Surg. 2018;105:1160-7.

4. Liu ZP, Miao Q, Liu XR, Zhang CJ, Tao G, Liu JZ. Outcomes of surgery for functional cardiac paragangliomas: a single-center experience of 17 patients. J Thorac Cardiovasc Surg. 2019;157:1556-64.

5. Trepa M, Silveira I, Amaral C, Luz A. Innovative approach to a functional mediastinal paraganglioma with anomalous coronary supply: a case report. Eur Heart J Case Rep. 2020;4:1-6.
See Article page 158.

\section{Commentary: What lessons can a surgeon learn from something rare?}

\author{
Kenza Rahmouni, MDCM, and \\ Fraser D. Rubens, MD, MSc, FACS, FRCSC
}

Primary cardiac paragangliomas (PCPs) are rare neuroendocrine tumors of the heart. In this issue of the Journal, Chan and colleagues ${ }^{1}$ share their center's experience in managing patients with PCP, presenting a cohort of 19 patients with a perioperative mortality of $10.6 \%$. The surgical steps are complex yet through experience and wise application of oncologic principles, this center is now a site of established excellence.

So how does the average cardiac surgeon interpret this type of presentation? Even in academic centers, one anticipates that these cases will be few and far between, and it should be recognized that we should support focusing this cohort into the hands of a few experts in each country. A better lesson from this manuscript is a template of how to address rare surgical diseases in general, be they from cancer or from other uncommon cardiac mechanical problems.

The authors have identified several principles that are critical to success. First, they have emphasized the importance of a large volume to efficiently turn experience into

From the Division of Cardiac Surgery, University of Ottawa Heart Institute, Ottawa, Ontario, Canada.

Disclosures: The authors reported no conflicts of interest.

The Journal policy requires editors and reviewers to disclose conflicts of interest and to decline handling or reviewing manuscripts for which they may have a conflict of interest. The editors and reviewers of this article have no conflicts of interest.

Received for publication Oct 6, 2020; revisions received Oct 6, 2020; accepted for publication Oct 7, 2020; available ahead of print Oct 17, 2020.

Address for reprints: Fraser D. Rubens, MD, MSc, FACS, FRCSC, University of Ottawa Heart Institute, 40 Ruskin St, Ottawa, Ontario, Canada K1Y 4W7 (E-mail: FRubens@ottawaheart.ca).

J Thorac Cardiovasc Surg 2022;164:168-9

$0022-5223 / \$ 36.00$

Copyright (c) 2020 by The American Association for Thoracic Surgery

https://doi.org/10.1016/j.jtcvs.2020.10.032
Check for updates

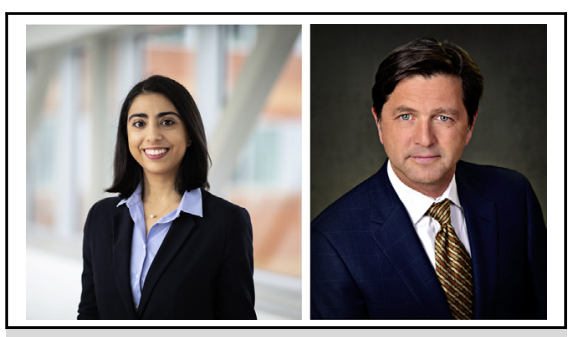

Kenza Rahmouni, MDCM (left), and Fraser D. Rubens, MD, MSc, FACS, FRCSC (right)

\section{CENTRAL MESSAGE \\ Surgical outcomes are intimately related to surgeon and institution expertise. We therefore must further centralize the care of rare cardiac tumors and refer patients to specialists earlier.}

reproducible surgical strategies. We know well the intimate relationship of surgical outcomes with institution expertise. A concrete example of this correlation is the experience in San Diego in managing chronic thromboembolic pulmonary hypertension with pulmonary endarterectomy. ${ }^{2}$ Over 50 years, their surgical outcomes for this highly subspecialized operation have consistently improved despite growing complexity of their cases. They are the center of excellence, frequently managing patients with chronic thromboembolic pulmonary hypertension deemed non-surgical in other centers.

The second important facet of success involves contribution from a multidisciplinary team, a strategy that has been recommended for more than 25 years for patients with 